Received: December 3, 2017

Revision received: May 2, 2018

\title{
Design and Implementation of JAVA-based Piano Teaching Management System*
}

\author{
Zhuo Nie ${ }^{1}$ \\ BeiHua University
}

\begin{abstract}
This paper analyzed the status quo and problems of piano teaching informatization, and proposed the design of piano teaching management system based on JAVA language and SSH framework. With this technology, by comparing the existing relatively mature technology framework and the development language, this paper set the B/S system architecture as the usage architecture and the SSH framework as the hierarchical structure of the system main body. Then JAVA was used on the basis of the structural design concept to design and implement the system. The completed piano teaching management system has been successfully applied to piano teaching management. After testing and application, the system has been fully functional and has basically reached the desired goal.
\end{abstract}

\section{Keywords}

Piano Teaching $\bullet$ B/S Architecture $•$ SSH Framework $•$ JAVA Language

\footnotetext{
* This work is supported by the Jilin Provincial Department of Education 13th Five-Year social science plan (Grant No. JJKH20170072SK).

1 Correspondence to: Zhuo Nie (MA), College of Music, BeiHua University, Jilin 132013, China. Email: niezhuo@beihua.edu.cn

Citation: Nie, Z. (2018). Design and Implementation of JAVA-based Piano Teaching Management System. Educational Sciences: Theory \& Practice, 18(5), 1660-1669. http://dx.doi.org/10.12738/estp.2018.5.065
} 
In Chinese teaching system, teaching can be divided into many different categories, including art education, culture and sports education, and scientific research education. It can be seen that art education is also an important component of Chinese education. According to statistics, the number of people who have participated in the piano grade examination has exceeded 300,000 since the beginning of the year when China began to implement the piano amateur grade examination, and it still shows a trend of increasing year by year, especially since the enrolment expansion of universities in our country. With the increasing people accepting higher education, there has been a further upsurge of piano learning (Gelding, Thompson \& Johnson, 2015; Lengers, Britz \& Holmmüller, 2013; Queirós \& Leal, 2013). Although many students have relatively weak piano foundations, they have unique understandings and preferences for the piano and have begun the piano learning, which makes it difficult for the school's relatively weak piano teaching resources to meet the demands of the students in the new era (OuYang, 2014).

At present, in the traditional management system of music education in colleges and universities, some colleges and universities have problems such as difficulty in the allocation of piano rooms, poor management integration, and low efficiency. In terms of efficiency, some colleges and universities only pay attention to the investment and construction of hardware facilities, while problems have arisen in the construction of some nuanced software supporting facilities, which has greatly discounted the organizational effectiveness of music teaching and the learning atmosphere and seriously affected the management efficiency of schools (Akçayır et al., 2016).

\section{JAVA and JSP Technology}

\section{JAVA Language}

The JAVA programming language is an object-oriented programming language officially launched by a well-known company (now acquired by Oracle Corporation). When designing JAVA language, in order to make the new JAVA language more attractive to programmers, designers introduce a large number of features of $\mathrm{C}$ language and object-oriented $\mathrm{C}++$ language, which also makes JAVA language resemble $\mathrm{C}++$ language to a certain extent but not an enhanced or Internet version of C++ (Davis, Dang, Pindrik, Rocque \& Johnston, 2016). JAVA language is not compatible with $\mathrm{C}++$ language. It eliminates the difficult-to-grasp and error-prone technical concepts such as frequently used pointers and polymorphic inheritance. At the same time, it designs a memory automatic recovery mechanism, eliminating the need for programmers to manage memory in programming, reducing the difficulty of memory management in program design and improving the overall system operating security. At the same time, when the compiler compiles the program, the output is not the directly executable binary code, but the byte code (byte code is converted from a virtual machine to a binary code that can be recognized for implementation, realizing the cross-platform execution of JAVA language (Martín-Gutiérrez et al., 2015).

JAVA language is an object-oriented language. In programming, objects are abstracted into classes, and the designed object structures can be independent of each other. JAVA language is open-source, and provides a 
wealth of open source frameworks, which can not only improve the stability of the system framework, but also facilitate the system's code design.

\section{JSP Technology}

JSP is a kind of system page design and development technology that exists mainly on the server side. JSP technology was proposed by Sun Microsystems. In the later application, a number of companies participated in the amendments to JSP technical specification, until the current commonly used mature page design JSP technology. JSP technology is dynamic and has similar aspects with the ASP technology proposed by Microsoft. The difference between the two is mainly due to the difference in the JSP technology system, resulting in a great difference in the application environment. The implementation system pages are generally composed of codes, script programs, server-side tags, etc., with .JSP as the file extensions. The implementation of the JSP technical page is not highly or even barely dependent on the system. Therefore, the application of the JSP technology in the system's page script and server-side can bring the system a better cross-platform performance and portability (Akçayır, \& Akçayır, 2017).

\section{Structured Design Method}

The structured method is more traditional and mainly includes three types, namely structural analysis, structured design, and structured programming. The idea of structured design is to divide a relatively complex system problem into several sub-problems, then to solve each sub-system separately, and finally to integrate the solution of each sub-problem to form a solution to the complex problem (Hua, Li, Zheng \& Xu, 2009; Ellen, Ulrich \& Hannah, 2013).

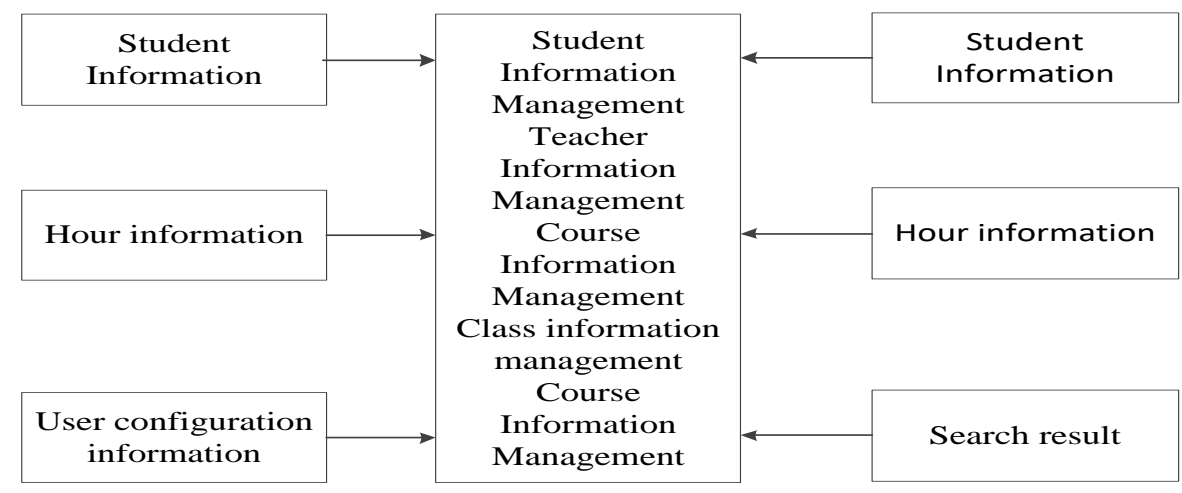

\section{Figure 1. System total IPO map.}

In the structured design method, the top-down design idea is used to get the optimal solution process. Based on the most basic foundations and principles, combined with practical experience, the process of solving complex problems is determined. In the process of solving a complex problem, the main technical means used 
are structured time language, data flow diagram, decision table, and data dictionary to ensure that the interpretability of the solution to the system problem is sufficiently strong. The system structure is shown in Figure 1.

\section{$\mathrm{C} / \mathrm{S}$ and $\mathrm{B} / \mathrm{S}$ structure}

At present, most of the test system structure is mainly based on C/S (Client/Server) structure and B/S (Browser/Server) structure (Figure 2). Test system based on C / S structure was used computer LAN. The contents of the test was on the remote server, the test machine installed the test application. Because of the use of the computer network and its structural characteristics, it only applies to a certain range of network internal (LAN). For each exam or version upgrade, the machine must be installed, the maintenance was difficult. Test applications put on the client, security is also affected easily.

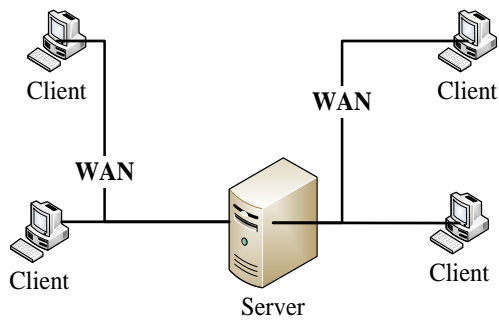

$\mathrm{C} / \mathrm{S}$ structure

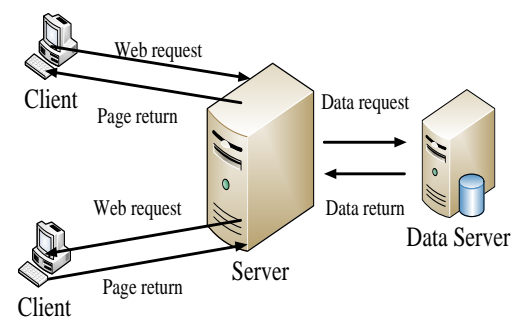

(b) B/S structure

Figure 2. C/S and B/S structure.

B/S uses three-tier structure, namely: the browser/ server, web database server, structure of the network test system. The client only needs to install a standard Web browser, other applications are stored on the web server, receiving the web page request and data request of the browser, and processing the web page request. The data request to the database server through the database interface program to the database server. The database server carries out the corresponding database operation through the database interface program to send back to the web server. Web server will handle the results to the browser to receive the form, sent back to the browser request, then display the results.

This B/S structure of the network test system for an examination room or dozens of test centers stand ten thousands of people at the same time. The test system on the client software over-reliance reducing the client software maintenance workload. Test system installation and test questions easily loaded and unloaded, simply by installing the server. B/S structure of the network examination system will not be time and geographical restrictions, this is the future development direction of the examination system.

\section{System Model Construction and Structural Design}

\section{Information Management Functions}

The basic function of the piano teaching management system is to manage the information of all trainees in each training class. In this way, the comprehensive management of all students in the university or training class 
can be strengthened, with instant information of students reported in real time. The trainee information management function includes the addition of trainees, the editing of trainees, the query of trainees, and the deletion of trainees. Figure 3shows the diagram of student information management process, while the table shows the specifications for the student information management.

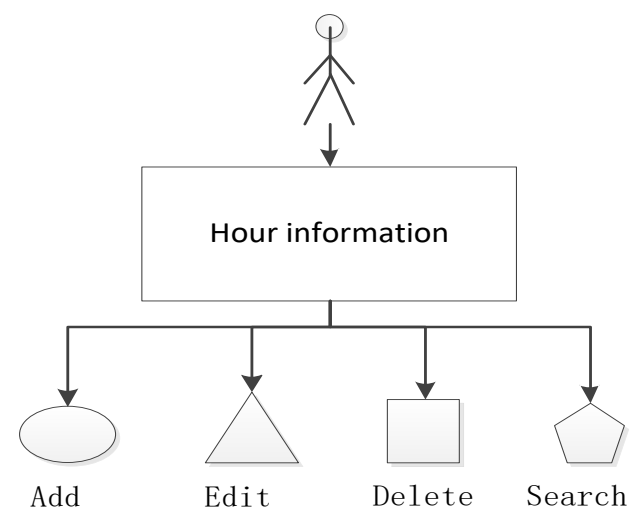

Figure 3. System Management Information.

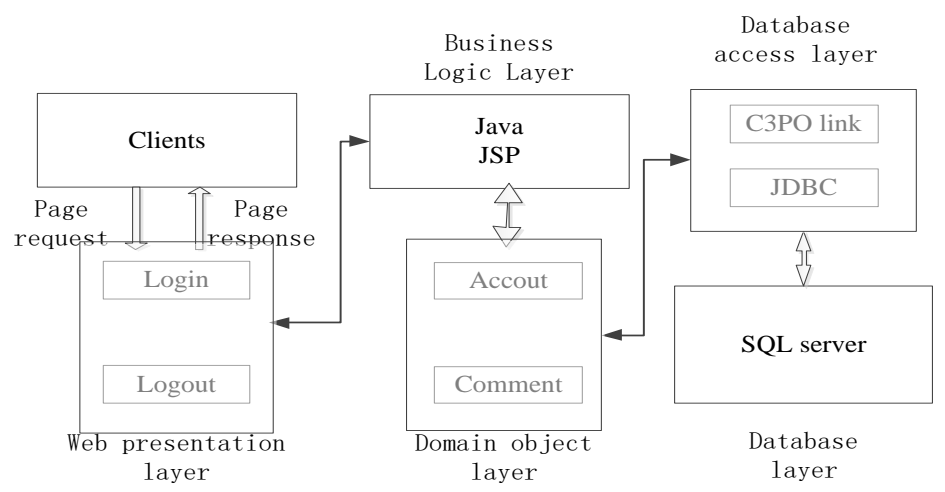

Figure 4. Overall system structure.

\section{System Architecture Design}

In the realization of the piano teaching management system, this paper mainly used the framework (i.e. the $\mathrm{SSH}$ and B/S pattern) that can not only separate views, processing controllers and databases, and logical layer and persistence layer, but also reduce the coupling among modules and levels and increase the aggregation among modules. As the independence increases between levels, changes at one level have less impact on other levels. If information in the front-end application layer changes, we only need to make corresponding changes to the middle tier in the model. Figure 4 shows the overall structure of the system. 
For the analysis of functional and non-functional requirements of the piano teaching management system, the design and implementation of the system mainly provides a convenient, efficient and reasonable platform for the piano teaching management department to improve the technical, electronic and scientific level of the teaching management. In the piano teaching management system, six function modules need to be provided. These are student information management module, teacher information management module, curriculum information management module, class information management module, timetable information management module, and system maintenance management module, with each containing several sub-function modules.

\section{System structure and function}

\section{The user logs module}

User can set a random verification code to achieve. After the user enters the user name and password, select the login role, and then submit the login, login will first test the user input data is legal. Illegal prompts the user to re-enter, legitimate inspection, submitted to the background processing, if the user's user name and the password is correct, the user role will jump to the appropriate interface, if the user name or password is wrong, it will remind the user to re-enter. User login module flow chart was shown in Figure 5:

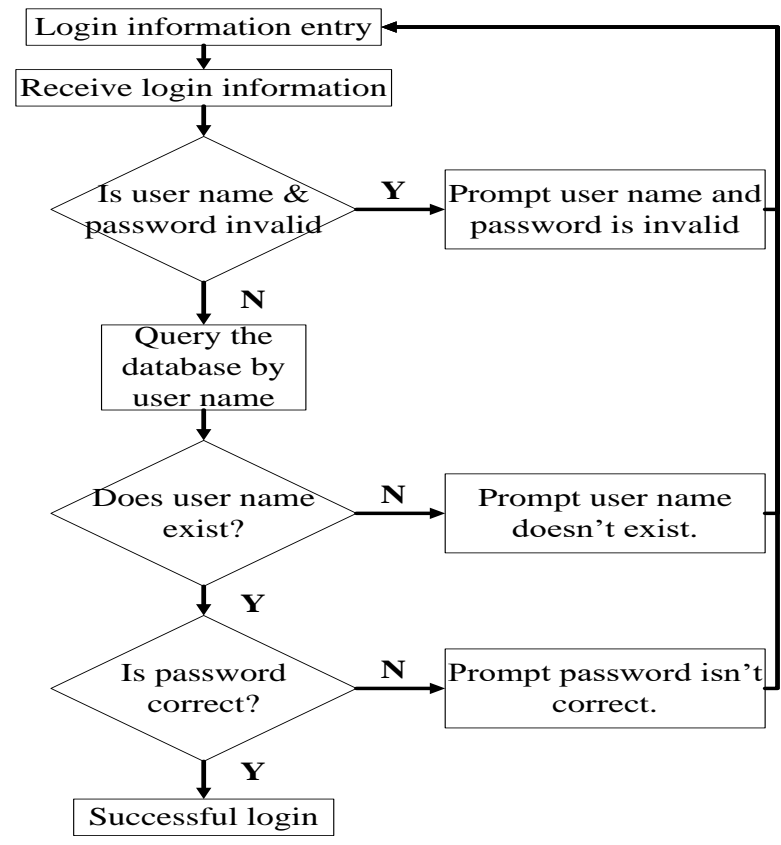

Figure 5. User login module flow chart. 


\section{User personal information module}

User's personal information query module is the basis of the system, including the user password changes, personal information can be updated according to individual circumstances, especially with the student's academic year. The same account not needed upgrade for every new create account, another advantage is that you can track the individual's previous information, so more detailed understanding of the previous learning situation can get. Personal password modification is a key part of the system, the user can login in according to different periods of password changes, thereby increased the security of the system. User personal information management module of online test system was shown in Figure 6.

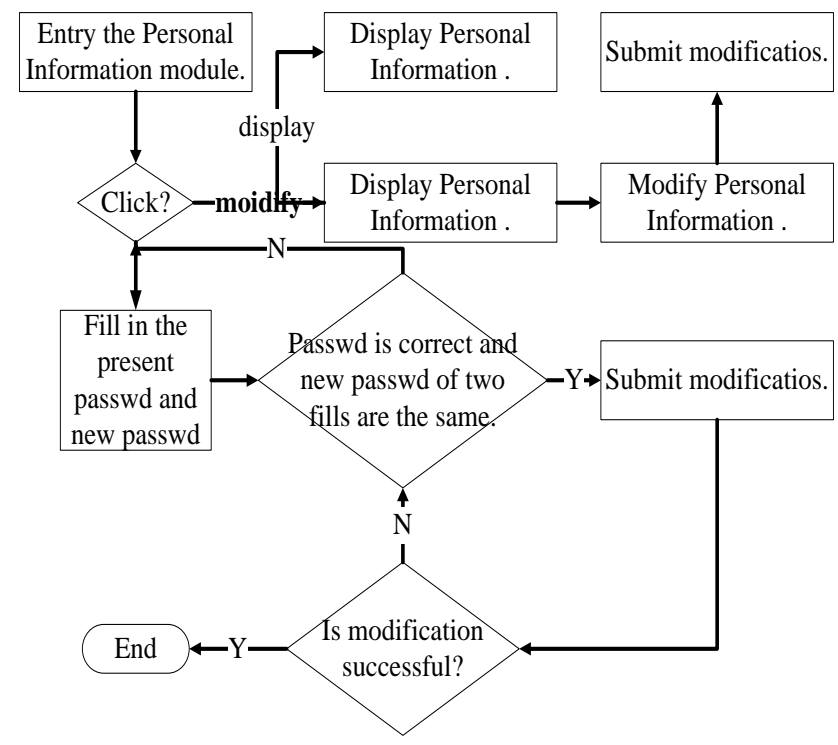

Figure 6. Personal information module flow chart.

When the user access to personal information module, there are three options. When click on the personal information query, you can display the basic information of individuals. When click on personal information changes, you can click the modified information which can be saved. When click on personal password changes, it will prompt the user to enter the current password, when enter the new password two times, click modify, the system will first detect the user's new password and alert user to re-enter the new password. The same link database will detect the user's existing password. If not correct, then return to prompt the user to re-fill, if correct, then submit the system to be updated.

\section{System Verification of Piano Teaching Management System}

\section{System Development and Application Environment}

In terms of the development environment, this paper adopted MyEclipse as the development platform, Apache as the server, SQLServer2013 as the database server, and Java as the development language. And the 
computer environment required by the design is as follows. The operating system must be above windows 7 (Windows 10 is recommended), with the computer's memory higher than $2 \mathrm{G}$ and no compulsory requirements for the computer and browser (Chorme is recommended). And the browsing mode should be set to $1024 * 768$.

\section{Test Results}

As can be seen from Figure 7, the overall average response time is 4.023 seconds, while the average response time for login operations is 1.272 seconds.

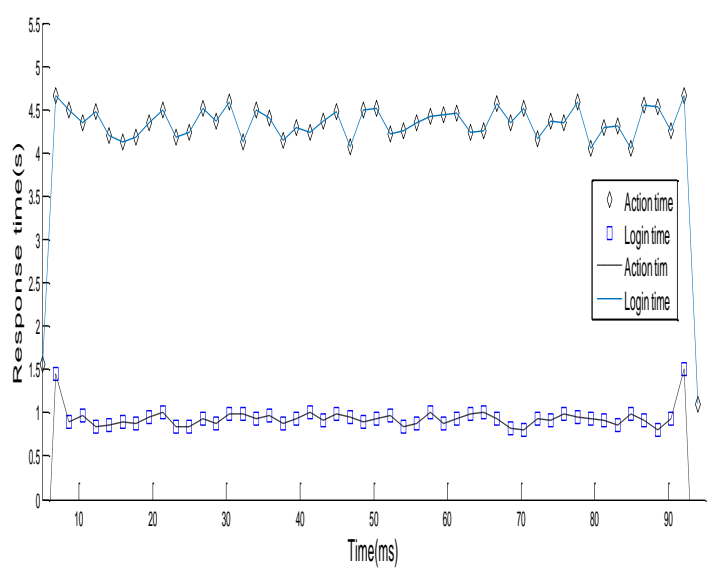

Figure 7. Action response.

According to the results shown in Figure 8, the server responds with an average of 6.562 times per second, and the average response for login events is 3.185 times per second. From the concurrent test of 300 use cases, it can be seen that the response speed of the system is faster with higher system stability.

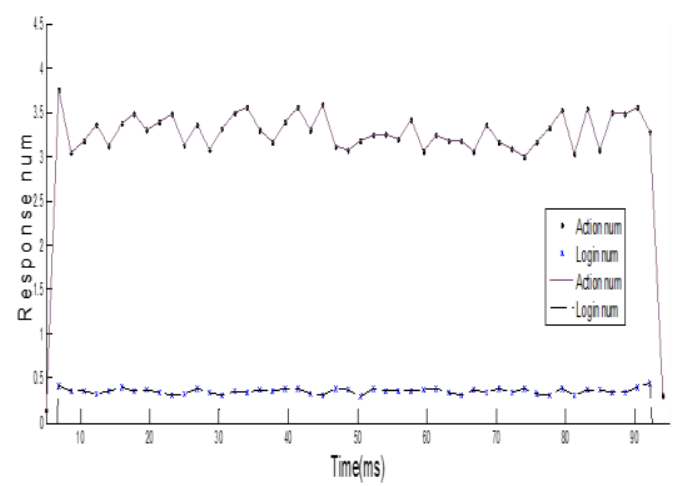

Figure 8. Server response. 


\section{Conclusion}

This paper analyzed the status quo and problems of piano teaching informatization, and proposed the design of piano teaching management system based on JAVA language and SSH framework. With this technology, by comparing the existing relatively mature technology framework and the development language, this paper set the $\mathrm{B} / \mathrm{S}$ system architecture as the usage architecture and the $\mathrm{SSH}$ framework as the hierarchical structure of the system main body. The experimental results show that the response speed of the system is faster with higher system stability.

\section{References}

Davis, M. C., Dang, D. T. C., Pindrik, J., Rocque, B. G., \& Johnston, J. M. (2016). Virtual interactive presence in global surgical education: International collaboration through augmented reality. World Neurosurgery, 86, 103-111. http://dx.doi.org/10.1016/j.wneu.2015.08.053

Ellen, S., Ulrich, S., \& Hannah, U. (2013). Reading amount as a mediator of the effects of intrinsic and extrinsic reading motivation on reading comprehension. Reading Research Quarterly, 48(4), 369-385. http://dx.doi.org/10.1002/rrq.52

Gelding, R. W., Thompson, W. F., Johnson, B. W. (2015). The pitch imagery arrow task: effects of musical training, vividness, and mental control. PloS One. 10(3), 1-10. http://dx.doi.org/10.1371/journal.pone.0121809

Hua, Z., Li, X. Q., Zheng, J. C., \& Xu, J. M. (2009). Research and implementation of Course Teaching-Learning Process Management System. IEEE International symposium on it in medicine \& education. IEEE. 1, 865871. IEEE. http://dx.doi.org/10.1109/ITIME.2009.5236299

Martín-Gutiérrez, J., Fabiani, P., Benesova, W., Meneses, M. D., \& Mora, C. E. (2015). Augmented reality to promote collaborative and autonomous learning in higher education. Computers in Human Behavior, 51, 752-761.http://dx.doi.org/10.1016/j.chb.2014.11.093

Lengers, B., Britz, W., \& Holmmüller, K. (2013). Comparison of GHG-emission indicators for dairy farms with respect to induced abatement costs, accuracy, and feasibility. Applied Economic Perspectives \& Policy, 35(3), 451-475. http://dx.doi.org/10.1093/aepp/ppt013

Akçayır, M., Akçayır, G., Pektaş, H. M., \& Ocak, M. A. (2016). Augmented reality in science laboratories: The effects of augmented reality on university students' laboratory skills and attitudes toward science laboratories. Computers in Human Behavior, 57, 334-342. http://dx.doi.org/10.1016/j.chb.2015.12.054

Akçayır, M., \& Akçayır, G. (2017). Advantages and challenges associated with augmented reality for education: A systematic review of the literature. Educational Research Review, 20, 1-11. http://dx.doi.org/10.1016/j.edurev.2016.11.002

OuYang, G. (2014). Design and Implementation of Student Information Management System Based on Java Technology. Applied Mechanics \& $\quad$ Materials, $\quad$ 687-691, 2474-2476. https://doi.org/10.4028/www.scientific.net/AMM.687-691.2474 
Queirós, R., \& Leal, J. P. (2013). crimsonHex: A learning objects repository for programming exercises. Software: Practice and Experience, 43(8), 911-935. http://dx.doi.org/10.1002/spe.2132 